\title{
Computational Design of Azo-anthraquinone Schiff Base Mn Complexes as Mediators for Biofuel Cell Cathode
}

Kazuto Kajiwara ${ }^{1}$, Shinsuke Yamane ${ }^{1}$, Tomoyuki Haraguchi ${ }^{1}$, Sayantan Pradhan ${ }^{2}$, Chittaranjan Sinha ${ }^{3}$, Rakesh Parida $^{4}$, Santanab Giri ${ }^{4}$, Gourisankar Roymahaptra ${ }^{5}$, Dohyun Moon ${ }^{6}$ and Takashiro Akitsu ${ }^{1}$

1. Department of Chemistry, Faculty of Science, Tokyo University of Science, Tokyo, Japan

2. Chemical Sciences Division, Saha Institute of Nuclear Physics, Kolkata, West Bengal, India

3. Department of Chemistry, Jadavpur University, Kolkata, West Bengal, India

4. Department of Chemistry, National Institute of Technology, Rourkela, India

5. Department of Applied Sciences, Haldia Institute of Technology, Haldia, West Bengal, India

6. Beamline Department, Pohang Accelerator Laboratory, Pohang, Korea

\begin{abstract}
The cathode of biofuel cell reduces molecular oxygen to water using four electrons, an enzyme of multicopper oxidase family, laccase, is contained, though its electron transfer efficiency from the electrode resulted in rate determining process. To improve this electron, transfer via mediators, we have investigated several mediator metal complexes between the electrode and laccase, in particular hydrophobic pocket on the surface. We have discussed DFT computational results and selected experimental data of new $\mathrm{Mn}(\mathrm{III} / \mathrm{II})$ Schiff base complexes having redox active (anthraquinone) ligands and photochromic (azobenzene) ligands about azobenzene moiety at the sole molecular level. Moreover, we carried out computational docking simulation of laccase and complexes considering trans-cis photoisomerization (electronic states) and Weigert effect (molecular orientation to fit better) of azobenzene moiety. Additionally, actual experimental data also presented to indicate the expected merits for mediators.
\end{abstract}

Key words: Laccase, Schiff base, Mn complex, anthraquinone, azobenzne, computational chemistry.

\section{Introduction}

(Bio) fuel cells are promising renewable power source for the sustainable development of the environment with reference in particular to green chemistry and technology [1]. Laccase, a multicopper oxidase (MCO) enzyme, reduces oxygen to water and has been used as enzyme on the cathode side of enzyme type biofuel cell [2-4]. Rate of cathodic reduction depends on the efficiency of long-range electron transfer process. To improve this electron transfer, we have investigated several types of metal complexes as mediators between the electrode and laccase [5-11]. Molecular docking of suitable compound (both ligands and complexes) to the hydrophobic pocket of laccase may be useful in

Corresponding author: Takashiro Akitsu, Ph.D., professor, research field: inorganic coordination chemistry. predicting the redox activity and their utility in biofuel cells [8, 9]. Presence of noncoordinating, non-innocent substituent to the ligand backbone in the metal ligand or complex may be induced by the polarized UV-light to control the rate of redox processes. In particular, the pendant azobenzene moiety can show Weigert effect (molecular alignment induced by polarized UV light) to control molecular orientation for suitable fitting $[10,11]$.

Herein, we present rationally molecular design of new $\mathrm{Mn}(\mathrm{III} / \mathrm{II}) \quad$ Schiff base $\quad\left(\mathrm{H}_{2} \mathrm{~L}^{1}=\right.$ 2-hydroxy-3-methoxy-5-phenyldiazobenzaldehydene1,2-diaminoanthraquino ne (1), $\quad \mathrm{H}_{2} \mathrm{~L}^{2}=$ 2-hydroxy-5-phenyldiazobenzaldehydene-1,2-diamino anthraquinone $\mathrm{H}_{2} \mathrm{~L}^{3}=$ 2-hydroxy-3-methoxy-5-phenyldiazobenzaldehydene2,3-diaminoanthraquinone (3)) complexes where a tetradentate dianionic $\mathrm{N}_{2} \mathrm{O}_{2}$ core is obtained by the 


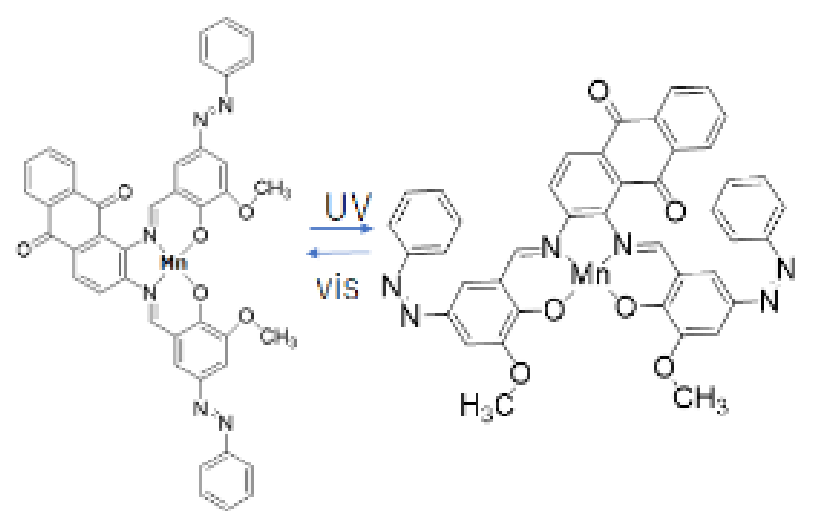

Scheme 1 Trans (left) - cis (right) photoisomerization of 1.

condensation of 1,2-diaminoanthraquinone and 2-hydroxy-3-methoxy-5-phenyldiazobenzaldehyde,

1,2-diaminoanthraquinone and

2-hydroxy-5-phenyldiazobenzaldehyde, or

2,3-diaminoanthraquinone

2-hydroxy-3-methoxy-5-phenyldiazobenzaldehyde, respectively. The Schiff bases bear a redox active (anthraquinone) moiety and photochromic (azobenzene) moiety [11]. Actually only the best complex expected (1) (Scheme 1) are characterized structurally. Both electrochemical and photochromic properties are examined and have been compared with the DFT/TD-DFT computed functions and computational docking simulation to laccase which were carried out prior to actual experiments.

\section{Materials and Methods}

\subsection{General Procedure}

Chemicals and solvents were of commercial grade obtained from SIGMA-ALDRICH, Tokyo Chemical Industry, and Wako, especially metal salts from SIGMA-ALDRICH. These were used as received without further purification.

\subsection{Physical Measurements}

Infrared (IR) spectra were recorded as $\mathrm{KBr}$ pellets on a JASCO FT-IR 4200 plus spectrophotometer in the range $4,000-400 \mathrm{~cm}^{-1}$ at $298 \mathrm{~K}$. UV-vis spectra were obtained on a JASCO V-570 UV-vis-NIR spectrophotometer in the range 1,500-200 nm at 298
K. Electrochemical (cyclic voltammetry, CV) were carried out on a BAS SEC2000-UV/VIS and ALS2323 system with $\mathrm{Ag} / \mathrm{AgCl}$ electrodes range of $-0.50-0.80 \mathrm{~V}$ vs. $\mathrm{Ag} / \mathrm{Ag}^{+}$.

\subsection{Preparations}

2-Hydroxy-3-methoxy-5-phenyldiazobenzaldehyde, and 2-hydroxy-5-phenyldiazobenzaldehyde (as precursors of $\mathrm{H}_{2} \mathrm{~L}^{1}$ and $\mathrm{H}_{2} \mathrm{~L}^{2}$ ) were prepared according to the literature procedure using the corresponding precursor aldehydes [11]. Each of them (0.06 g, 0.25 mmol) was added to a methanol solution $(80 \mathrm{~mL})$ of 1,2-diaminoanthraquinone (SIGMA-ALDRICH) (0.13 $\mathrm{g}, 0.5 \mathrm{mmol})$ to stir for $2 \mathrm{hr}$ at $318 \mathrm{~K}$, then $\mathrm{Mn}\left(\mathrm{CH}_{3} \mathrm{COO}\right)_{2} \cdot 4 \mathrm{H}_{2} \mathrm{O}$ (SIGMA-ALDRICH) $(0.061 \mathrm{~g}$, $0.025 \mathrm{mmol}$ ) was added to stir for $2 \mathrm{hr}$ at $318 \mathrm{~K}$. Brown crude product was obtained by filtration after evaporation and the product was recrystallized from hexane and dried to give rise to 1 or 2 .

1: Yield $18.0 \%$. IR $\left(\mathrm{KBr}, \mathrm{cm}^{-1}\right) 715(\mathrm{~m}), 838(\mathrm{w})$, 1019(w), 1127(w), 1164(w), 1193(w), 1303(s), 1328(m), 1382(m), 1439(m), 1531(s), 1588(m), 1625(m), 3268(m), 3414(s).

2: Yield $12.7 \%$. IR (KBr, $\left.\mathrm{cm}^{-1}\right) 715(\mathrm{~m}), 838(\mathrm{w})$, 1019(w), 1164(w), 1193(w), 1303(s), 1329(m), 1380(m), 1441(m), 1531(s), 1588(m), 1624(m), 3270(m), 3414(s).

\subsection{X-ray Crystallography}

Powder X-ray diffraction patterns of 1 were collected at $298 \mathrm{~K}$ at Pohang Light Source II 2D Supramolecular Crystallography Beamline (PLSII-2D-SMC). Powder was packed in the $0.5 \mathrm{~mm}$ diameter (wall thickness is $0.01 \mathrm{~mm}$ ) capillary and the diffraction data measured transparency as Debye-Scherrer at $298 \mathrm{~K}$ respectively, with the 100 $\mathrm{mm}$ of detector distance in $10 \mathrm{sec}$ exposures with synchrotron radiation $(\lambda=1.20007 \AA)$ on an ADSC Quantum-210 detector at 2D SMC with a silicon (111) double crystal monochromator (DCM) at the Pohang Accelerator Laboratory, Korea. The PAL BL2D-SMDC 
Table 1 Crystallographic data for 1.

\begin{tabular}{ll}
\hline & 1 \\
\hline Empirical formula & $\mathrm{C} 42 \mathrm{H} 28 \mathrm{MnN6O6}$ \\
Formula weight & 767.64 \\
Temperature / K & 298 \\
Crystal system & Triclinic \\
Space group & $\mathrm{P}-1$ \\
$a / \AA$ & $17.20(2)$ \\
$b / \AA$ & $26.21(3)$ \\
$c / \AA$ & $11.670(15)$ \\
$\alpha /{ }^{\circ}$ & $97.38(8)$ \\
$\beta / /^{\circ}$ & $94.90(6)$ \\
$\gamma /{ }^{\circ}$ & $104.67(7)$ \\
$V /\left(A^{3}\right)$ & $5418(27)$ \\
$Z$ & 2 \\
$\mathrm{D} / \mathrm{gcm}{ }^{-3}$ & 0.430 \\
$\mathrm{~F}(000)$ & 726 \\
$S$ & 11.2135 \\
$R w p(\%)$ & 14.73 \\
\hline
\end{tabular}

program [12] was used for data collection, and Fit2D program [13] was used converted 2D to $1 \mathrm{D}$ pattern and wavelength and detector distance refinement. Rietveld analysis 20 was carried out with a Rigaku PDXL2 ver.2.2.1.0, commercially available program package by the following procedures: indexing, cell and space group determination, input composition and initial structural model from DFT, direct space method, addition of displacement parameters for non-hydrogen atoms, and refinement with hydrogen atoms under restraint. Crystallographic data are listed in Table 1.

\subsection{Computational Methods}

Calculations of all complexes were performed using the Gaussian 09W software Revision D.02 (Gaussian, Inc.) [14]. All the geometries have been optimized by using B3LYP level of theory and SDD as basis set. Also, we performed frequency calculation on optimized geometry by using same level of theory and basis set also.

Docking of metal complexes has been performed out with AutoDock 4.2.6 on windows platform with 8 GB RAM and Intel I 5 processor [15].

\section{Results and Discussion}

\subsection{Synthesis and Formulation}

As mentioned in later sections about computational results, only 1 and 2 were prepared actually. In IR spectra, characteristic $\mathrm{C}=\mathrm{N}$ bands of imine groups coordinating to $\mathrm{Mn}$ (II) ion appeared at 1,625 and $1,624 \mathrm{~cm}^{-1}$ for 1 and 2, respectively. Which are similar to analogous $\mathrm{Mn}$ (II) complexes [16], and this feature exhibits high-wavenumber shift comparing to common Schiff base Mn(III) complexes $\left(1,616 \mathrm{~cm}^{-1}\right.$, [17]). Hence air oxidation of $\mathrm{Mn}$ (II) as prepared to $\mathrm{Mn}$ (III) immediately [18] during reaction did not occur. Selected possible assignments of other bands for example 1 are as follows: 715( $\delta \mathrm{CH}), 1127(\mathrm{C}-\mathrm{O})$, 1303(C-N), 1439(Ar), 1588(Ar), 1625(C=O), and $3414 \mathrm{~cm}^{-1}(\mathrm{O}-\mathrm{H})$.

UV-vis spectra appeared intense $\pi-\pi^{*}$ and $n-\pi^{*}$ peaks and moderate d-d peaks at 270, 345, and 540 $\mathrm{nm}$ for 1 and 275, 345, and $545 \mathrm{~nm}$ for 2, which were typical features of a square planar Schiff base Mn(II) complex with azo-ligand in a ground spin state [10]. Introduction of methoxy group makes them blue shifts. For 1, trans to cis photoisomerization after UV light irradiation (and also reverse changes by visible light) attributed to spectral changes, namely slight decrease of intensity around $270 \mathrm{~nm}$ of $\pi-\pi^{*}$ band, significant decrease of intensity around $345 \mathrm{~nm}$ of $\mathrm{n}-\pi^{*}$, and drastic blue shift 550 to $450 \mathrm{~nm}$ of d-d band. However, 2 did not exhibit smooth photoisomerization.

Complex 1 affords a four-coordinated slightly distorted square planar trans- $\left[\mathrm{N}_{2} \mathrm{O}_{2}\right]$ coordination geometry. Fig. 1 shows the crystal structure of 1 with Mn1-O1 = 1.771(3), Mn1-O4 = 1.781(2), Mn1-N1 = 1.903(3), Mn1-N4 = 1.883(2) ̊̊, O1-Mn1-N1 = 171.405(16), O4-Mn1-N4 = 172.763(13) ${ }^{\circ}$ ). Within the precision of powder analysis, ligand moiety (such as $\mathrm{N} 2-\mathrm{N} 3=1.2304(15) \AA$, N5-N6 = 1.2474(17) $\AA$ ) exhibited normal values of geometry, which was similar to DFT optimized structure (see next section). Of course, not only in solutions (but also in crystals), 


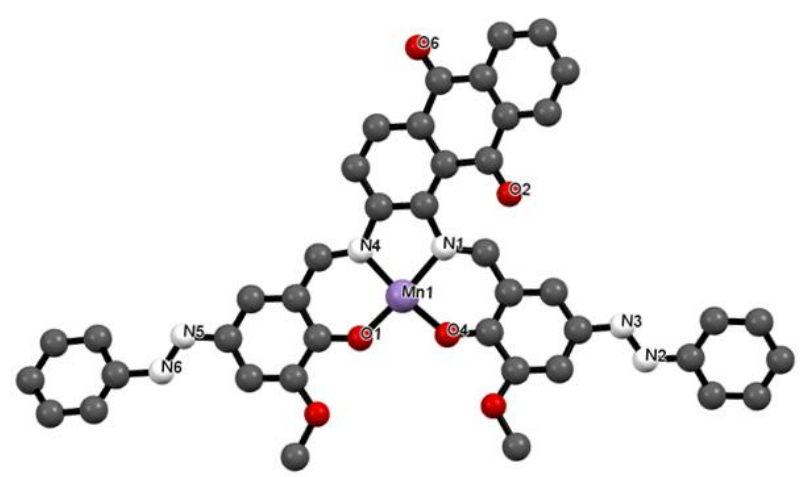

Fig. 1 Crystal structure of 1 analyzed from powder diffraction data.

empty apical sites accept axial ligands such as water or solvents molecules potentially [10].

\subsection{Selection of Ligands}

By using TD-DFT, candidate molecules were examined prior to actual experiments. Figs. 2-4 depict optimized structures of trans-form of 1-3 assuming as sextet states, respectively. Total energies were $-2,500.674,-2,271.662$, and $-2,271.675$ a.u., respectively. HOMO and LUMO energies were as follows: alpha $\mathrm{HOMO}=-0.377,-0.392,-0.402$ a.u. beta $\mathrm{HOMO}=-0.366,-0.370,-0.372$ a.u. alpha LUMO $=-0.301,-0.305,-0.303$ a.u. LUMO $=-0.357$, $-0.362,-0.364$ a.u. for trans-forms of 1-3, respectively. Calculated UV-vis spectra appeared intense peaks at 549.429, 525.534, and $535.060 \mathrm{~nm}$, respectively. In this way, methoxy group more importantly contributed to spectral shift than anthraquinone moiety of the ligand, and comparison between 1 and 2 may be useful for molecular design reasonably. Additionally, PDOS with orbital contribution and UV-vis spectra and possible transitions in 1-3 (and their $\mathrm{Cu}(\mathrm{II})$ analogues for comparison) were also shown in Supplementary Information 1 and 2.

\subsection{Cis-trans Photoisomerization of Ligands}

Assuming photoisomerization of azobenzene moiety vertially, trans-forms (see section 3.2) and cis-forms were compared not only for 1-2 but also their $\mathrm{Cu}$ (II) analogues. According to DFT results, all complexes could be expected to exhibit cis-trans

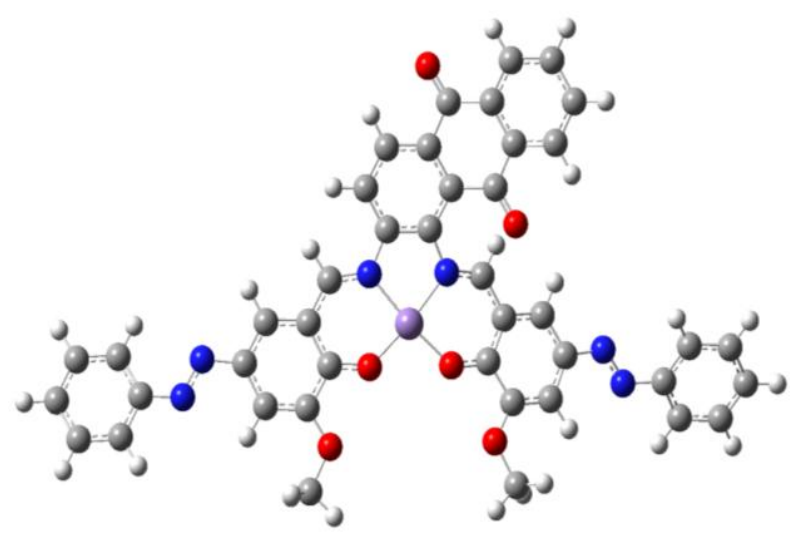

Fig. 2 Optimized structure of 1.

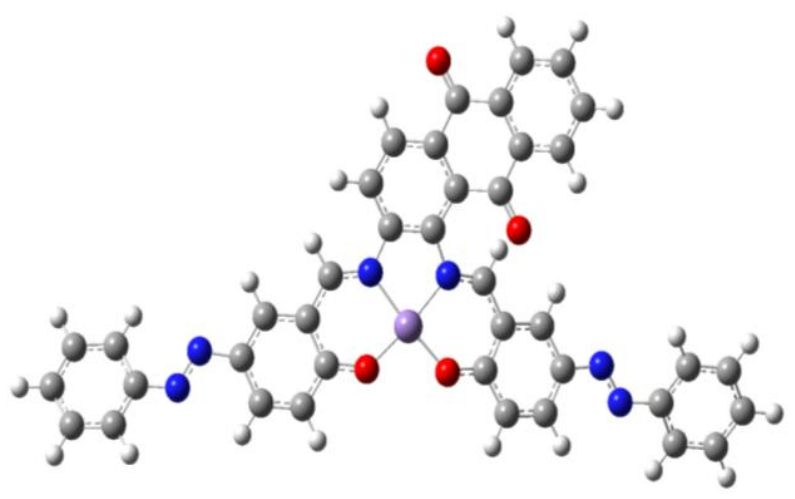

Fig. 3 Optimized structure of 2.

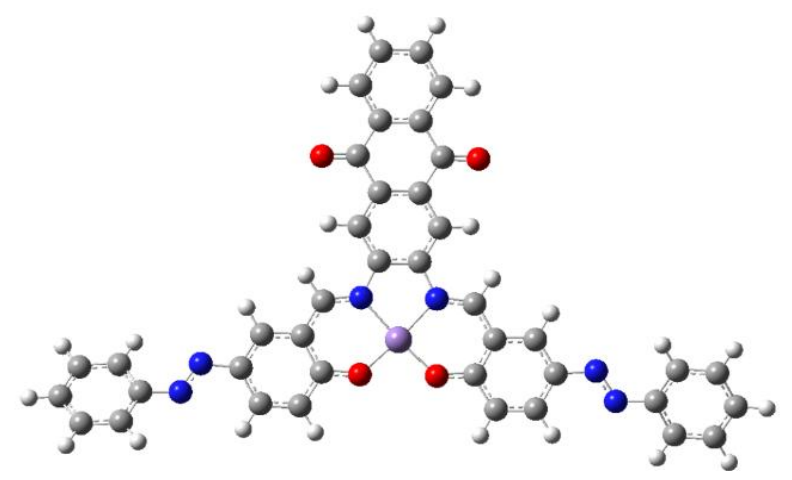

Fig. 4 Optimized structure of 3.

photoisomerization with significant changes. Large shifts of optical absorption associated with redox potentials of $c i s$-form of 1 indicated that it may be the most appropriate complexes among them for the purpose as mediators. Total energies were -2,500.672 and $-2,271.615$ a.u., respectively. HOMO and LUMO energies were as follows: alpha $\mathrm{HOMO}=-0.355$ and -0.384 a.u. beta $\mathrm{HOMO}=-0.352$ and -0.357 a.u. alpha LUMO $=-0.324$ and -0.339 a.u. LUMO $=-0.339$ and -0.350 a.u. for cis-form of 1 and 2, respectively. 
Calculated UV-vis spectra appeared intense peaks at 836.26 and $605.598 \mathrm{~nm}$, respectively. Additionally, PDOS with orbital contribution and UV-vis spectra and possible transitions in 1 and 2 were also exhibited in Supplementary Information 3 and 4.

\subsection{Docking of Complexes into Laccase}

By using simulation, docking ability to laccase for 1-3 was investigated as follows. The A chain of laccase is modified by removing water and bound ligand. Missing amino acids have been checked and hydrogen bonds have been added to the protein structure. Center Grid box x:16.895, y:5.931, z:37.151 and number of points in $\mathrm{x}, \mathrm{y}, \mathrm{z}$ dimensions are considered as $30 \times 30 \times 30 \AA^{3}$ respectively and grid spacing has been taken as $0.3750 \AA$. The protein (Laccase) and ligand (complexes) structures have been modified by Autodock Tools. Ligands have been prepared by adding Gasteiger charges, detecting root and choosing torsions from torsion tree of Autodock Tools panel [19]. Docking procedure has been performed by using Lamarckian genetic algorithm [20]. The best-fit ligand conformations were selected based on their minimum binding energies.

Docking scores of complexes (DFT optimized structures) to crystal structure of laccase (retrieved from PDB 1qyc) were $-9.6,-8.3$, and $-7.9 \mathrm{kcal} / \mathrm{mol}$ for trans-forms of 1-3, respectively. On the other hand, docking scores of the corresponding $\mathrm{Cu}$ complexes were $-9.7,-9.2$, and $-8.7 \mathrm{kcal} / \mathrm{mol}$ for trans-forms of $1-3$ 's $\mathrm{Cu}$ (II) analogues, respectively. The results indicated that docking scores mainly depend on structures of ligands, and ligand 1 was the best fit ligand among three as trans form.

\subsection{Docking of cis Form Assuming Polarized UV Light Irradiation.}

Importance of trans-cis isomerization of azo-group (by UV natural light irradiation), orientation change (by UV polarized light irradiation, so-called Weigert effect $[10,11])$, or both was simulated by comparison of trans- and cis- forms of 1 to fit laccase surface. Indeed, the docking scores were -9.6 and $-9.6 \mathrm{kcal} / \mathrm{mol}$, because steric factor due to photoisomerization was not conclusive in this case. Unfortunately, molecular orientation by Weigert effect was not clear based on the results. However, electronic factors calculated also proved that cis-form of 1 was the best fit mediator, though not only trans- (Fig. 5) but also cis-form (Fig. 6) of 1 can similarly fit to laccase according to simulation. Secondary structure of laccase receptor represented by ribbon model, and cis-form of 1 is represented by ball and stick model.

A table of Supplementary Information 5 listed detailed data of docking of cis-form of 1 through hydrophobic, electrostatic, and hydrogen bonding interactions. Comprehensive perception of laccase receptor and cis-form of 1 interaction after docking. The cis-form of 1 is docked near T1 active site of laccase receptor on surface.

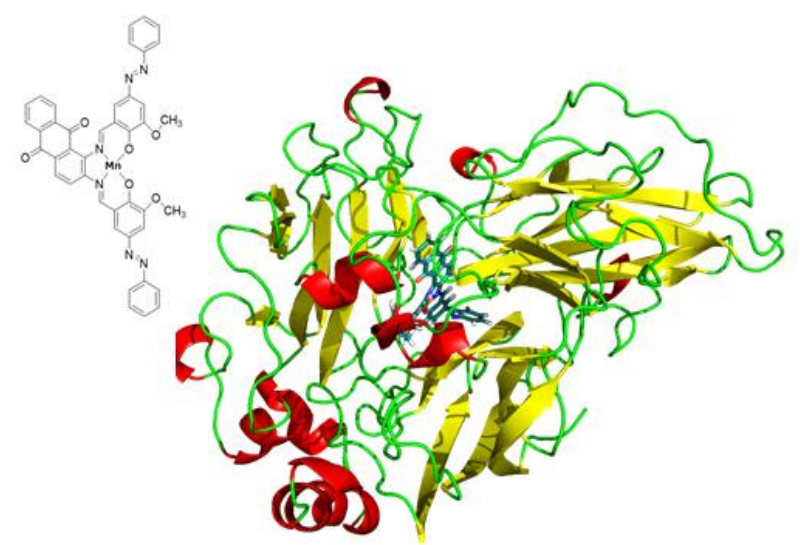

Fig. 5 Docking simulation of trans-form of 1 and laccase.

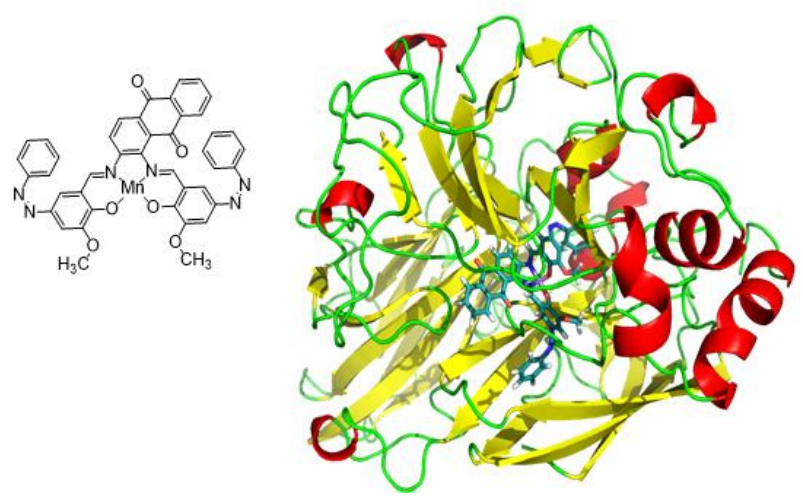

Fig. 6 Docking simulation of cis-form of 1 and laccase. 


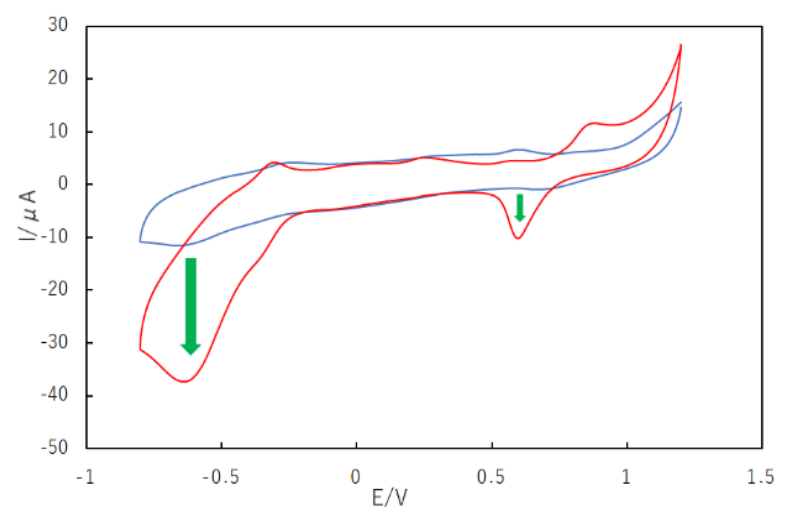

Fig. 7 CV (as glassy carbon electrode) of laccase containing (trans-)1 under nitrogen (blue) and oxygen (red) atmosphere.

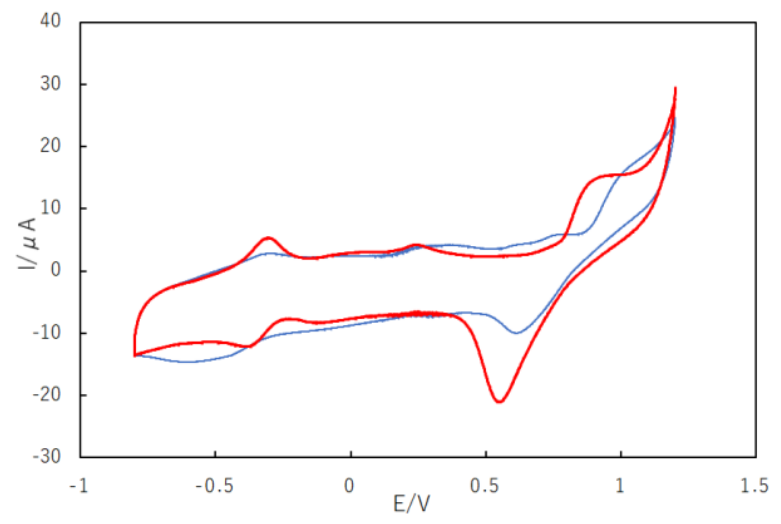

Fig. 8 CV (measured with grassy carbon) 1 after photoisomerization. Red: UV 0 min (trans), Green: UV 5 min (cis), Blue: UV 10 min (cis).

\subsection{Electrochemistry}

Changes of UV-vis spectra (in DMSO solution), decreasing $\mathrm{n}-\pi^{*}$ band intensity around $450 \mathrm{~nm}$ after UV light irradiation, shown in in Supplementary Information 6 suggested that the azo-ligand complex solely exhibited smooth photoisomerization in a solution.

Fig. 7 shows $\mathrm{CV}$ (as glassy carbon electrode) of laccase containing (trans-form of) 1 under nitrogen and oxygen purged atmosphere. Increasing current under oxygen atmosphere suggested that reduction of oxygen occurred effectively by $1[10,11]$. However, both are measured as trans-forms, because photoisomerization could not be observed in laccase's hydrophobic pocket for this complex, contrary to glassy carbon environment (Fig. 8). Supramolecular hybrids of laccase and metal complex, especially actual features of unsuitable molecular recognition, made impossible to use not only photoisomerization but also photo-induced orientation of azo-ligand.

\section{Conclusions}

In this way, a computationally-driven style in screening of suitable complexes was carried out, contrary to a conventional style, namely preparations, characterizations, and computational consideration. The only best complex 1 with laccase was examined experimentally to proof an assumption of molecular design by screening.

\section{$<$ Computational tests>}

- DFT of complex molecules $(1,2,3)$ in Section 3.2

- DFT of cis-trans photoisomerization $(1,2)$ in Section 3.3

- Docking of a complex into laccase (1) in Section

\section{4}

$<$ Experimental tests>

- Characterization (1, partly 2) in Section 3.1

- Electrochemistry (1) in Section 3.6

As expected by computation of three candidates, we have experimentally measured changes UV-vis and $\mathrm{CV}$ of 1 solely showing cis-trans photoisomerization of azo-group smoothly. Purged gas CV exhibited effective oxygen reduction by laccase with mediator of 1 was confirmed because of spatial advantage. However, trans-cis photoisomerization and/or Weigert effect of azobenzene moiety were not observed clearly for 1 as docking to laccase due to unsuitable molecular recognition actually.

\section{Supplementary data}

PDOS with Orbital Contribution, UV-vis spectra and possible transitions, details of docking and UV-vis (DMSO) by photoisomerization are provided.

\section{Acknowledgment}

The synchrotron X-ray crystallography experiment 
at PLS-II BL2D-SMC beamline was supported in part by MSIT and POSTECH. The laboratory XRD work was partly conducted at the Advanced Characterization Nanotechnology Platform of the University of Tokyo (Prof. Kazuhiro Fukawa), supported by the Nanotechnology Platform of the Ministry of Education, Culture, Sports, Science and Technology (MEXT), Japan.

\section{References}

[1] Mano, N., and de Poulpiquet, A. 2018. "O${ }_{2}$ Reduction in Enzymatic Biofuel Cells.” Chem. Rev. 118: 2392 and references therein.

[2] Agbo, P., Heath, J. R., and Gray, H. B. 2014. "Modeling Dioxygen Reduction at Multicopper Oxidase Cathodes." J. Am. Chem. Soc. 136: 13882.

[3] Winkler, J. R., and Gray, H. B. 2014. "Long-Range Electron Tunneling.” J. Am. Chem. Soc. 136: 2930.

[4] Crane, B. R., Di Billio, A. J., Winkler, J. R., and Gray, H. B. 2001. "Electron Tunneling in Single Crystals of Pseudomonas Aeruginosa Azurins." J. Am. Chem. Soc. 123: 11623.

[5] Kurosawa, Y., Tsuda, E., Takase, M., Yoshida, N., Takeuchi, Y., Mitsumoto, Y., and Akitsu, T. 2015. Threonine: Food Sources, Functions and Health Benefits. NY, USA: Nova Science Publishers.

[6] Ogikubo, Y., Sano, A., Nagano, K., and Akitsu, T. 2016. Laccase: Applications, Investigations and Insights. NY, USA: Nova Science Publishers.

[7] Ogikubo, Y., and Akitsu, T. 2016. "Enhancing Medical or Biological Functions of Laccase by Cyanide-Bridged $\mathrm{Cu}(\mathrm{II})-\mathrm{Fe}(\mathrm{III})$ Bimetallic Complexes Madiators." Drug Designing: Open Access 5: 130.

[8] Takeuchi, Y., and Akitsu, T. 2016. "Anthraquinone Derivative Chiral Schiff Base Copper(II) Complexes for Enzyme Type Bio-Fuel Cell Mediators." J. Elect. Eng. 4: 189.

[9] Takeuchi, Y., Sunaga, N., and Akitsu, T. 2017. "Anthraquinone and L-amino Acid Derivatives Schiff Base $\mathrm{Cu}$ (II) Complexes as a Mediator between Cathode of Biofuel Cell and Oxygen-reducing Laccase." Trends in Green Chem. 3: 1.

[10] Mitsumoto, Y., Sunaga, N., and Akitsu, T. 2017.
"Polarized Light Induced Molecular Orientation in Laccase for Chiral azo-salen $\mathrm{Mn}(\mathrm{II}), \mathrm{Co}(\mathrm{II}), \mathrm{Ni}(\mathrm{II}), \mathrm{Cu}(\mathrm{II})$, $\mathrm{Zn}(\mathrm{II})$ Mediators toward Application for Biofuel Cell." Sci. Fed. J. Chem. Res. 1: 1.

[11] Sano, A., Yagi, S., Haraguchi, T., and Akitsu, T. 2018. "Synthesis of MnII and CuII Complexes Including a Zobenzene and Its Application to Mediators of Laccase for Biofuel Cells.” J. Indian. Chem. Soc. 95: 487.

[12] Shin, J. W., Eom, K., and Moon, D. 2016. "BL2D-SMC, the Supramolecular Crystallography Beamline at the Pohang Light Source II, Korea.” J. Synchrotron Rad. 23: 369.

[13] Fit2D program: Andy Hammersley (E-mail: hammersley@esrf.fr), ESRF; 6 RUE JULES HOROWITZ BP 22038043 GRENOBLE CEDEX 9 FRANCE.

[14] Frisch, M. J., Trucks, G. W., Schlegel, H. B., Scuseria, G. E., Robb, M. A., Cheeseman, J. R., Scalmani, G., Barone, V. et al. 2009. Gaussian 09, Revision D.01, Gaussian, Inc., Wallingford CT, 2009.

[15] Morris, G. M., Huey, R., Lindstrom, W., Sanner, M. F., Belew, K. R., Goodsell, D. S., and Olson, A. J. 2009. "AutoDock4 and AutoDockTools4: Automated Docking with Selective Receptor Flexibility." J. Comput. Chem. 30: 2785.

[16] Akitsu, T., and Tanaka, R. 2011. "Polarized Spectroscopy and Polarized UV Light-induced Molecular Orientation of Chiral Diphenyl Schiff Base $\mathrm{Ni}$ (II) and $\mathrm{Cu}$ (II) Complexes and Azobenzene in a PMMA Film." Current Phys. Chem. 1: 82.

[17] Akitsu, T., Takeuchi, Y., and Einaga, Y. 2005. "Diaqua(N,N'-bis(3,5-dibromosalicylidene)(1R,2R)-1,2-d iaminocyclohexanato- $\left.\kappa^{4} \mathrm{O}, \mathrm{N}, \mathrm{N}^{\prime}, \mathrm{O}^{\prime}\right)$ manganese(III)) Perchlorate Dehydrate." Acta Cryst. E61: m772.

[18] Okamoto, Y., Nidaira, K., and Akitsu, T. 2012. Crystallography: Research, Technology and Applications. NY, USA: Nova Science Publishers, Inc.

[19] Gasteiger, J., and Marsili, M. 1980. "Iterative Partial Equalization of Orbital Electronegativity-A Rapid Access to Atomic Charges." Tetrahedron. 36: 3219.

[20] Morris, G. M., Goodsell, D. S., Halliday, R. S., Huey, R., Hart, W. E., Belew, R. K., and Olson, A. J. 1998. "Automated Docking Using a Lamarckian Genetic Algorithm and an Empirical Binding Free Energy Function." J. Comput. Chem. 19: 1639. 
S.I. 1. PDOS with Orbital Contribution of trans-forms of 1-3.

trans-form of 1
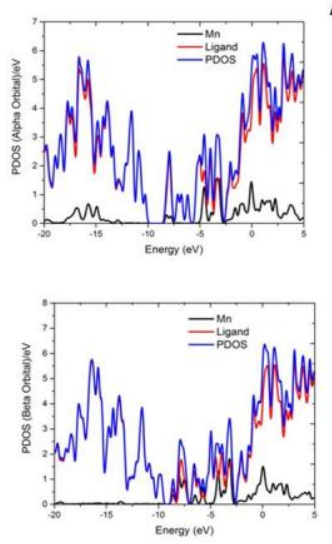

trans-form of 2

$\begin{array}{ccc}\text { Alpha MOS } & \text { Mn } & \text { Ligands } \\ \text { L+5 } & 1 & 99 \\ \text { L+4 } & 2 & 98 \\ \text { L+3 } & 23 & 97 \\ \text { L+2 } & 0 & 100 \\ \text { L+1 } & 6 & 94 \\ \text { WMO } & 28 & 72 \\ \text { HOMO } & 1 & 99 \\ \text { H-1 } & 0 & 100 \\ H-2 & 0 & 100 \\ H-3 & 1 & 99 \\ H-3 & 0 & 100 \\ H-4 & 0 & 100 \\ \text { H-5 } & 0 & 100 \\ & & \end{array}$

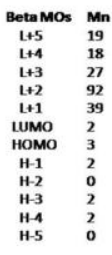

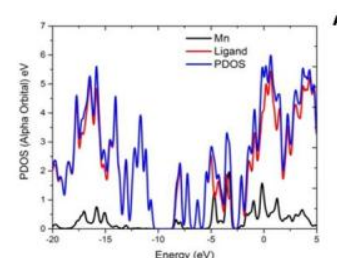

$\begin{array}{cc}\text { Alpha MOs } & \text { Mn } \\ \text { L+5 } & 1 \\ \text { L+4 } & 1 \\ \text { L+3 } & 3 \\ \text { L+2 } & 21 \\ \text { L+1 } & 1 \\ \text { WMO } & 31 \\ \text { HOMO } & 1 \\ H-1 & 0 \\ H-2 & 1 \\ H-3 & 0 \\ H-3 & 0 \\ H-4 & 0 \\ H-5 & 0\end{array}$

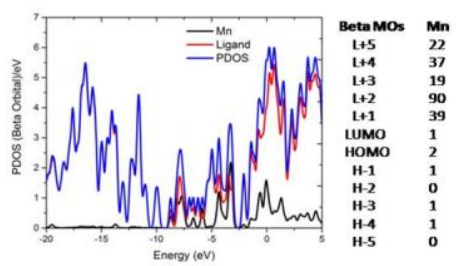

trans-form of 3
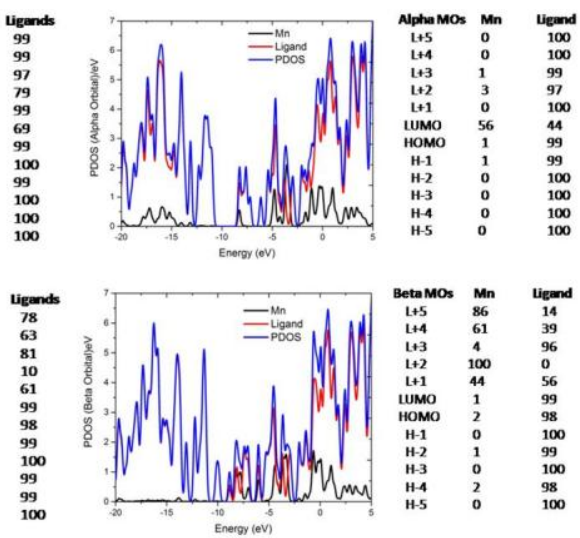

S.I. 2. UV-VIS Spectra and possible transitions in trans-forms of 1-3 and $\mathrm{Cu}(I I)$ analogues

1 and its $\mathrm{Cu}(\mathrm{II})$ analogue2
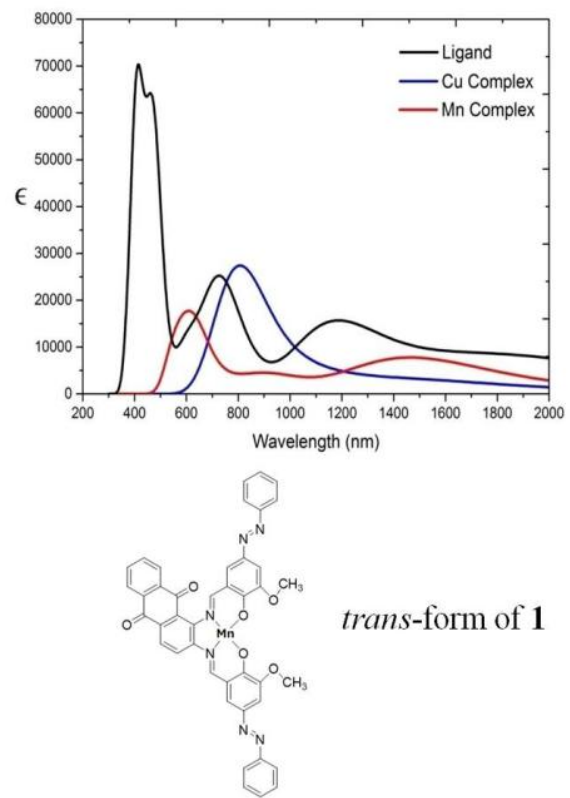

\begin{tabular}{|c|c|c|c|c|c|}
\hline & \begin{tabular}{|l|} 
Wavelengt \\
$\mathrm{h}(\mathrm{nm})$
\end{tabular} & \begin{tabular}{|l|} 
Osc \\
Strength
\end{tabular} & Symmetry & Major Contribution & Minor Contribution \\
\hline \multirow[t]{4}{*}{$\mathrm{H}_{2} \mathrm{~L}^{1}$} & 400.556 & 0.2 & \begin{tabular}{|c|} 
Singlet- \\
$\mathrm{A}$
\end{tabular} & $\begin{array}{c}\mathrm{H}-1->\mathrm{L}+3 \quad(18 \%), \\
\mathrm{H}-1->\mathrm{L}+4 \quad(25 \%), \\
\text { HOMO->L+5 }(24 \%)\end{array}$ & $\begin{array}{l}\text { H-17->LUMO }(4 \%), \\
\text { H-12->LUMO }(3 \%), \text { HOMO->L+4 }\left(9 \frac{1}{6}\right)\end{array}$ \\
\hline & \begin{tabular}{|l|}
480.038 \\
\end{tabular} & 0.3 & \begin{tabular}{|c|} 
Singlet- \\
$\mathrm{A}$
\end{tabular} & $\begin{array}{ll}\text { HOMO->L+2 } & (53 \%), \\
\text { HOMO- }>\mathrm{L}+4 & (10 \%)\end{array}$ & $\begin{array}{l}\text { H-16-> LUMO (6\%), } \\
\text { H-15-> LUMO (3\%), } \\
\text { H-13-> LUMO }(2 \%), \\
\text { H-12-> LUMO (3\%), } \\
\text { H-7-> LUMO (4\%), } \\
\text { H-4->L+1 (3\%) }\end{array}$ \\
\hline & 734.286 & 0.2 & \begin{tabular}{|c|} 
Singlet- \\
$\mathrm{A}$
\end{tabular} & $\begin{array}{l}\text { H-5-> LUMO }(148), \\
\text { HOMO->L+1 } \\
\end{array}$ & \begin{tabular}{|l|} 
H-4-> LUMO \\
H-1->LUMO $(4 \%)$, \\
\end{tabular} \\
\hline & \begin{tabular}{|l|}
1180.35 \\
2
\end{tabular} & 0.2 & \begin{tabular}{|c|} 
Singlet- \\
$\mathrm{A}$
\end{tabular} & $\begin{array}{l}\text { H-1-> LUMO (76\%), } \\
\text { HOMO->LUMO }(21 \%)\end{array}$ & HOMO->L+1 (3) \\
\hline $\begin{array}{c}\mathrm{Cu}(\mathrm{II}) \\
\text { analogue } \\
\text { of } 1\end{array}$ & 837.109 & 0.06 & $2.590-\mathrm{A}$ & $\begin{array}{l}\text { H-5 (B) - } \\
>\text { LUMO (B) (12\%), } \\
\text { H-4 (B) ->L+1(B) } \\
(12 \%)\end{array}$ & 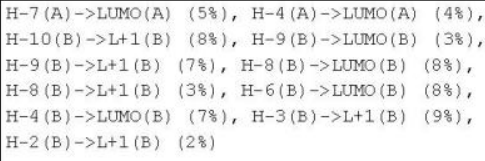 \\
\hline 1 & 549.429 & 0.1 & $6.259-\mathrm{A}$ & $\begin{array}{c}\mathrm{H}-1 \text { (B) }->\mathrm{L}+4(\mathrm{~B}) \\
(32 \%)\end{array}$ & 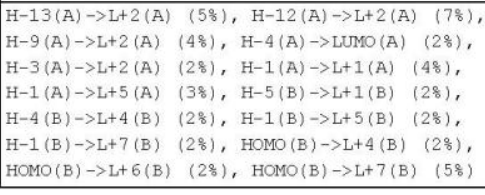 \\
\hline
\end{tabular}


Continued.

2 and its $\mathrm{Cu}(\mathrm{II})$ analogue

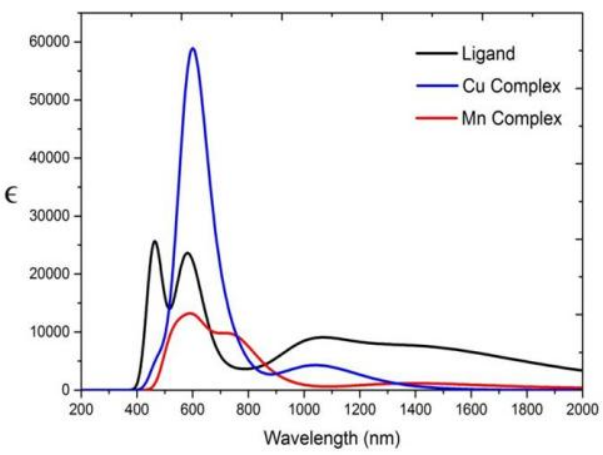

\begin{tabular}{|c|c|c|c|c|c|}
\hline & \begin{tabular}{|l}
$\begin{array}{l}\text { Wavelength } \\
(\mathrm{nm})\end{array}$ \\
\end{tabular} & \begin{tabular}{|l|} 
Osc \\
Strength
\end{tabular} & Symmetry & Major Contribution & Minor Contribution \\
\hline \multirow[t]{4}{*}{$\mathrm{H}_{2} \mathrm{~L}^{2}$} & 470.136 & 0.1 & Singlet $-A$ & $\begin{aligned} \text { H-14->LUMO } & (248), \\
\text { HOMO->LL+5 } & (458)\end{aligned}$ & $\begin{array}{l}\text { H-16->LUMO }(48), \\
\text { H-4->L+3 }(38), \\
\text { H-1->L+4 }(28)\end{array}$ \\
\hline & 581.430 & 0.2 & Singlet-A & HOMO->L+3 $(80 \%)$ & 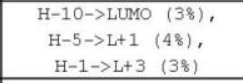 \\
\hline & 1036.224 & 0.1 & Singlet-A & $\begin{array}{l}\text { H-1->L+1 }(198), \\
\text { HOMO->L+1 }(78 \%)\end{array}$ & \\
\hline & 607.438 & 0.5 & $2.872-\mathrm{A}$ & $\begin{array}{l}\text { H-10 (A)>LUMO (A) (208), } \\
\text { H-6 (A) ->LUMO (A) (17\%), } \\
\text { H-3 (A) ->LUMO (A) (10\%), } \\
\text { H-11(B) ->LUMO (B) (14\%) }\end{array}$ & 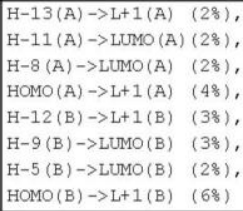 \\
\hline \begin{tabular}{|c|}
$\mathrm{Cu}(\mathrm{II})$ \\
analogue of 2
\end{tabular} & 525.534 & 0.09 & $6.213-\mathrm{A}$ & $\begin{array}{l}\text { H-10(A) }>\mathrm{L}+3(\mathrm{~A})(228), \\
\mathrm{H}-3(\mathrm{~A}) \rightarrow \mathrm{L}+5(\mathrm{~A})(10 \%), \\
\mathrm{HOMO}(\mathrm{B}) \rightarrow \mathrm{L}+7 \text { (B) }(10 \%)\end{array}$ & $\begin{array}{l}H-12(A)->L+3(A) \quad(48), \\
H-11(A)->L+3(A) \quad(3 \%), \\
H-10(A)->L+2(A) \quad(3 \%), \\
H-9(A)->L+3(A) \quad(2 \%), \\
H-7(A)->L+3(A) \quad(28), \\
H-3(A)->L+4(A) \quad(3 \%), \\
H-2(A)->L+3(A) \quad(3 \%), \\
H-1(A)->L+5(A) \quad(28), \\
H O M O(A)->L+5(A) \quad(38), \\
H-4(B)->L+4(B) \quad(28), \\
H-3(B)->L+4(B) \quad(38), \\
H O M O(B)->L+8(B) \quad(98)\end{array}$ \\
\hline 2 & 739.189 & 0.07 & $6.080-\mathrm{A}$ & $\begin{array}{l}\text { H-11 (B)>LUMO (B) (12\%), } \\
H-10 \text { (B)>LUMO (B) (11\%), } \\
\text { H-9 (B) ->LUMO (B) (50\%), } \\
H-1 \text { (B) ->L+1 (B) (15\%) }\end{array}$ & \\
\hline
\end{tabular}

Continued.

3 and its Cu(II) analogue

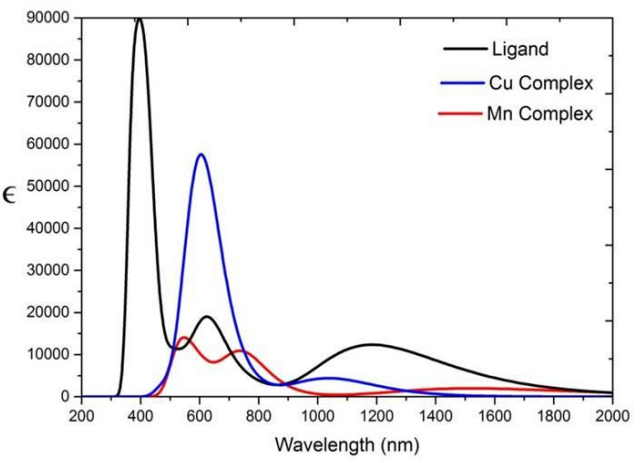

\begin{tabular}{|c|c|c|c|c|c|}
\hline & \begin{tabular}{|l} 
Wavelength \\
$(\mathrm{nm})$
\end{tabular} & \begin{tabular}{|l} 
Osc \\
Strength
\end{tabular} & Symmetry & Major Contribution & Minor Contribution \\
\hline \multirow[t]{4}{*}{$\mathrm{H}_{2} \mathrm{~L}^{3}$} & 389.055 & 0.3 & Singlet- $\bar{A}$ & $\begin{array}{l}\text { H-5 }>\text { L+ } 2 \quad(14 \%), \\
\text { HOMO->L+5 } \quad\left(53 \frac{\circ}{6}\right)\end{array}$ & $\begin{array}{l}\mathrm{H}-4->\mathrm{L}+2 \quad(3 \%), \\
\mathrm{H}-1->\mathrm{L}+4 \quad(3 \%), \\
\mathrm{H}-1->\mathrm{L}+5 \quad(5 \%), \\
\text { HOMO->L+3 }(5 \%), \\
\text { HOMO }>\text { L + } 4 \quad(4 \%)\end{array}$ \\
\hline & 415.302 & 0.5 & Singlet- $\bar{A}$ & $\begin{array}{l}\mathrm{H}-1->\mathrm{L}+2 \quad(14 \%) \\
\text { HOMO->L+3 }(40 \%)\end{array}$ & $\begin{array}{c}\text { H-16->LUMO (9\%), } \\
\text { H-15-> LUMO (6\%), } \\
\text { H-14->LUMO (3\%), } \\
\text { H-2->L+2 (3\%), } \\
\text { HOMO->L+4 (6\%), } \\
\text { HOMO->L+5 (3\%) }\end{array}$ \\
\hline & \begin{tabular}{|l|}
656.522070 \\
491
\end{tabular} & 0.1 & Singlet-A & $\begin{array}{cc}\text { H-4 }->\text { LUMO } & (61 \%), \\
\text { HOMO->L+1 } & (21 \%)\end{array}$ & $\begin{array}{l}\text { H-5-> LUMO }(4 \%), \text { H-1- } \\
>\text { LUMO }(2 \%), \text { HOMO->LUMO } \\
(2 \%)\end{array}$ \\
\hline & 595.391 & 0.4 & $2.899-\mathrm{A}$ & $\begin{array}{l}\text { H-11 }(A)>\text { LUMO }(A)(14 \%), \\
\text { HOMO }(A)->\text { L+1 (A) }(10 \%) \\
\text { H-10 (B) - LUMO (B) }(39 \%)\end{array}$ & 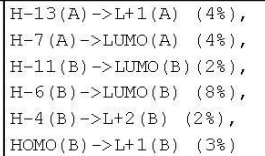 \\
\hline $\begin{array}{l}\mathrm{Cu}(11) \\
\text { analogue } \\
\text { of } 3\end{array}$ & 535.060 & 0.07 & $6.280-\mathrm{A}$ & 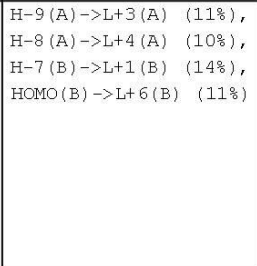 & 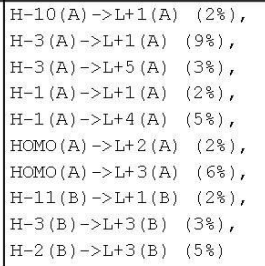 \\
\hline 3 & \begin{tabular}{|l|}
733.287159 \\
997
\end{tabular} & 0.1 & $6.074-A$ & $\begin{array}{l}\mathrm{H}-11(\mathrm{~B})->\mathrm{LITMO}(\mathrm{B}) \\
(11 \%), \mathrm{H}-10(\mathrm{~B})- \\
>\text { LUMO }(\mathrm{B}) \quad(75 \%)\end{array}$ & 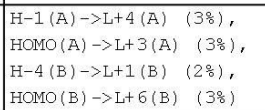 \\
\hline
\end{tabular}


S.I. 3. UV-VIS Spectra and possible transitions in trans-forms of 1-2

cis-form of 1

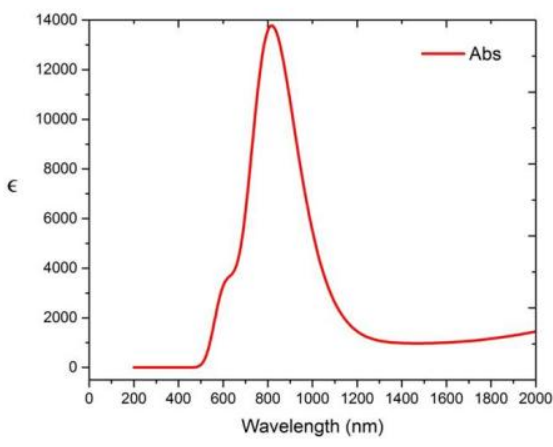

cis-form of $\mathbf{2}$

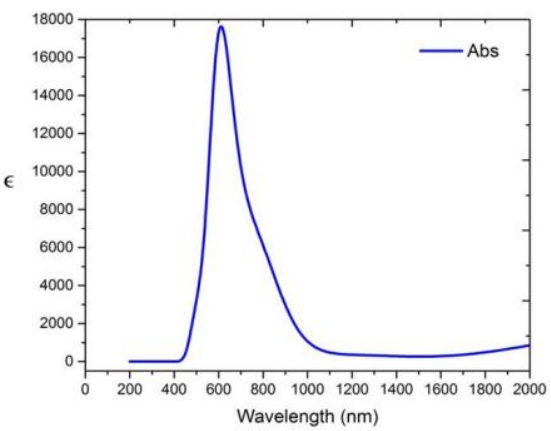

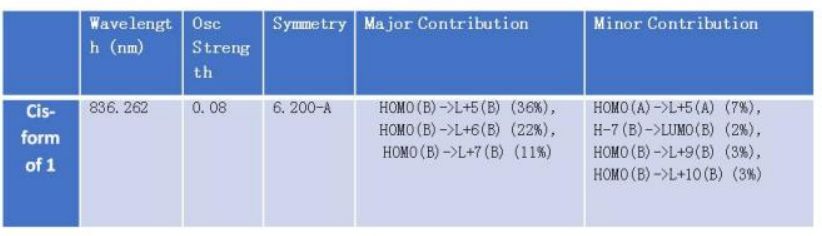

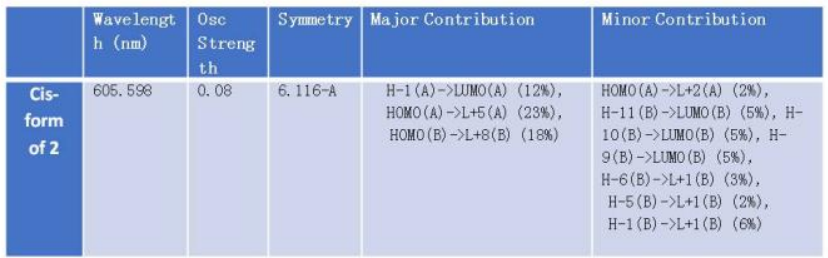

S.I. 4. PDOS with Orbital Contribution of cis-forms of 1-2.

cis-form of 1
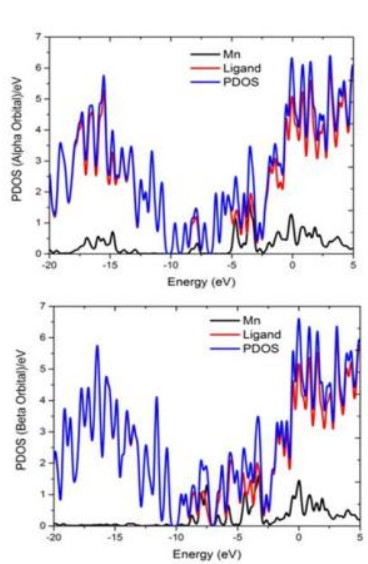

cis-form of $\mathbf{2}$

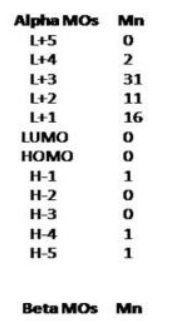

$\begin{array}{cl}\text { Beta MOS } & \text { Mn } \\ \text { L+5 } & 13 \\ 1+4 & 73 \\ 1+3 & 34 \\ L+2 & 7 \\ \text { L+2 } & 73 \\ \text { L+1 } & 33 \\ \text { UMO } & 2 \\ \text { HOMO } & 6 \\ H-1 & 2 \\ H-2 & 2 \\ H-3 & 2 \\ H-4 & 1 \\ H-5 & 0\end{array}$

\begin{tabular}{|l}
\hline Uigand \\
100 \\
98 \\
69 \\
89 \\
84 \\
100 \\
100 \\
99 \\
100 \\
100 \\
99 \\
99 \\
\\
\\
\hline ligand \\
87 \\
27 \\
66 \\
93 \\
67 \\
98 \\
94 \\
98 \\
98 \\
98 \\
99 \\
100
\end{tabular}

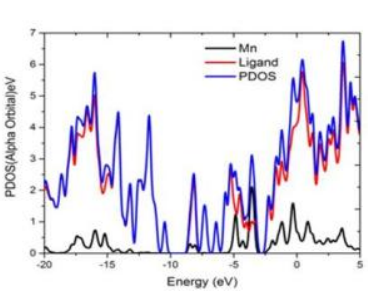

$\begin{array}{lcc}\text { Alpha MOS } & \text { Mn } & \text { Ligand } \\ \text { L+5 } & 1 & 99 \\ \text { L+4 } & 1 & 99 \\ \text { L+3 } & 25 & 75 \\ \text { L+2 } & 1 & 99 \\ \text { L+1 } & 1 & 99 \\ \text { LMO } & 29 & 71 \\ \text { HOMO } & 0 & 100 \\ \text { H-1 } & 1 & 99 \\ \text { H-2 } & 0 & 100 \\ \text { H-3 } & 0 & 100 \\ \text { H-4 } & 0 & 100 \\ \text { H-5 } & 0 & 100 \\ & & \end{array}$

ligand
87
27
66
93
67
98
94
98
98
98
99
100

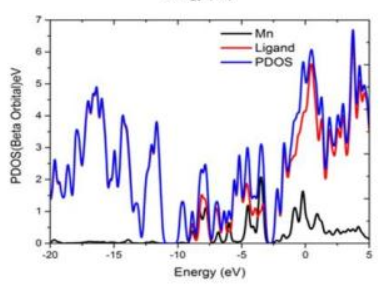

$\begin{array}{ll}\text { Beta MOS } & \text { Mn } \\ \text { L+5 } & 23 \\ \text { L+4 } & 33 \\ \text { L+3 } & 22 \\ \text { L+2 } & 84 \\ \text { L+1 } & 38 \\ \text { WMO } & 1 \\ \text { HOMO } & 3 \\ \text { H-1 } & 0 \\ \text { H-2 } & 0 \\ \text { H-3 } & 0 \\ \text { H-4 } & 1 \\ \text { H-5 } & 0\end{array}$

Ligand
77
67
78
16
62
99
97
100
100
100
99
100 

Mediators for Biofuel Cell Cathode

\section{S.I. 5. Details of docking cis-form of $\mathbf{1}$}

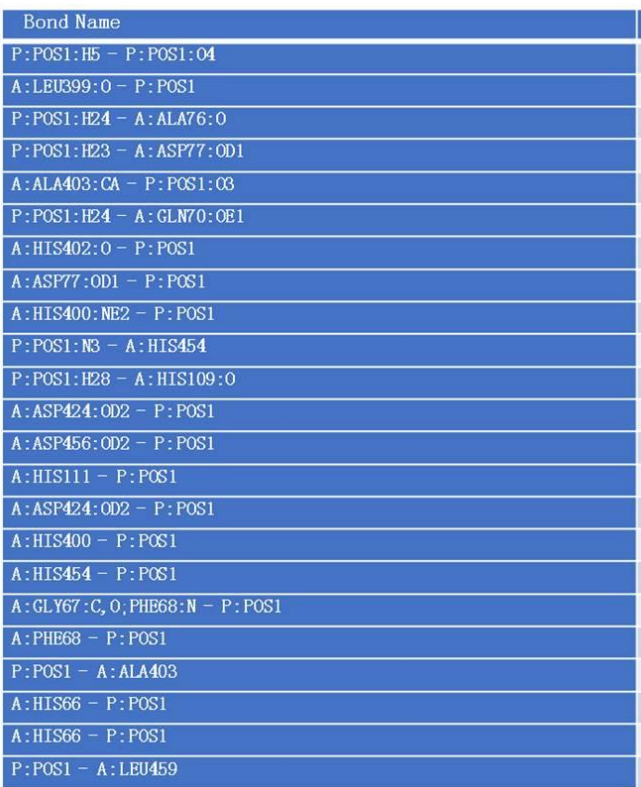

\begin{tabular}{|l|l|l}
\hline Distance $(\mathrm{A})$ & Bond category & Bond type \\
\hline 2.23683 & Hydrogen Bond & Carbon Hydrogen Bond \\
\hline 2.63499 & Other & Pi-Lone Pair \\
\hline 2.72308 & Hydrogen Bond & Carbon Hydrogen Bond \\
\hline 2.73455 & Hydrogen Bond & Carbon Hydrogen Bond \\
\hline 2.75161 & Hydrogen Bond & Carbon Hydrogen Bond \\
\hline 2.75375 & Hydrogen Bond & Carbon Hydrogen Bond \\
\hline 2.80636 & Other & Pi-Lone Pair \\
\hline 2.85246 & Electrostatic & Pi-Anion \\
\hline 2.90308 & Other & Pi-Lone Pair \\
\hline 2.91289 & Other & Pi-Lone Pair \\
\hline 2.92536 & Hydrogen Bond & Carbon Hydrogen Bond \\
\hline 3.12933 & Electrostatic & Pi-Anion \\
\hline 3.13155 & Electrostatic & Pi-Anion \\
\hline 3.40795 & Hydrophobic & Pi-Pi Stacked \\
\hline 3.71353 & Electrostatic & Pi-Anion \\
\hline 3.79501 & Hydrophobic & Pi-Pi Stacked \\
\hline 4.28387 & Hydrophobic & Pi-Pi Stacked \\
\hline 4.32737 & Hydrophobic & Amide-Pi Stacked \\
\hline 4.38413 & Hydrophobic & Pi-Pi Stacked \\
\hline 4.58791 & Hydrophobic & Pi-Alkyl \\
\hline 4.68749 & Hydrophobic & Pi-Pi Stacked \\
\hline 4.93692 & Hydrophobic & Pi-Pi Stacked \\
5.07549 & Hydrophobic & Pi-Alkyl \\
\hline & & \\
\hline
\end{tabular}

S.I. 6. UV-vis spectra (DMSO) of 1 during photoisomerization

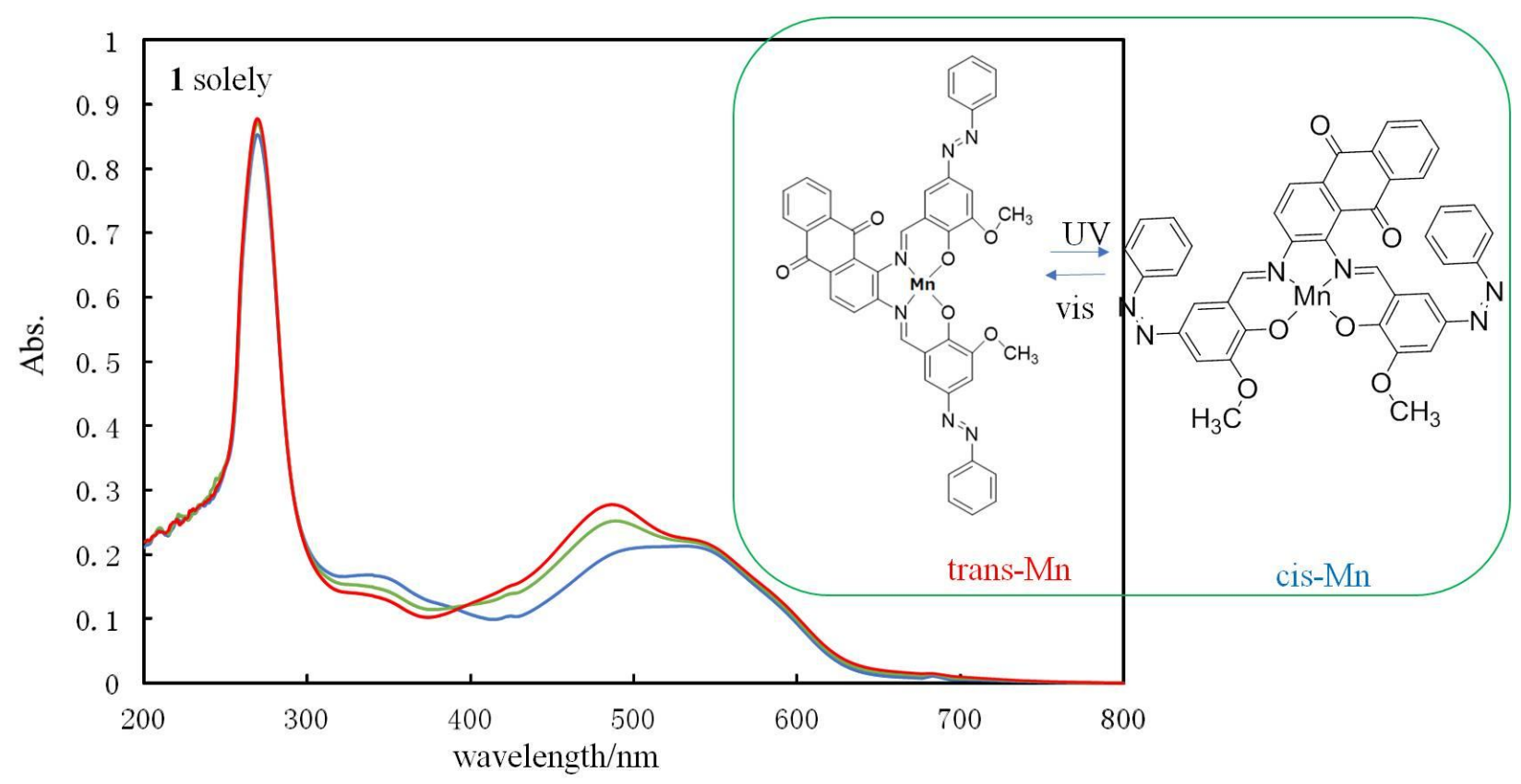

Red: UV 0 min (trans-form), Green: UV $5 \mathrm{~min}$, Blue: UV $10 \mathrm{~min}$ (cis-form) 